\title{
Future Seas 2030: pathways to sustainability for the UN Ocean Decade and beyond
}

\author{
Gretta T. Pecl - Karen A. Alexander • \\ Jess Melbourne-Thomas • Camilla Novaglio • \\ Cecilia Villanueva $\cdot$ Kirsty L. Nash
}

Published online: 21 February 2022

(C) The Author(s), under exclusive licence to Springer Nature Switzerland AG 2022

The United Nations has declared 2021-2030 as the UN Decade of Ocean Science for Sustainable Development. The objective is to motivate international efforts aimed at improving ocean health by providing the science necessary for sustainable development of the oceans-to underpin "The ocean we need for the future we want". This coordinated effort is urgently needed as demands for natural resources continue to escalate (Jouffray et al. 2020), and society is faced with managing these demands in the face of unprecedented environmental changes (IPCC 2019). However, major transformations are needed at all scales to create a sustainable future, and these are reliant

G. T. Pecl $(\bowtie) \cdot$ K. A. Alexander · J. Melbourne-Thomas ·

C. Novaglio $\cdot$ C. Villanueva $\cdot$ K. L. Nash

Centre for Marine Socioecology, University of Tasmania,

Private Bag 129, Hobart, TAS 7001, Australia

e-mail: Gretta.Pecl@utas.edu.au

G. T. Pecl · K. A. Alexander - C. Novaglio - C. Villanueva ·

K. L. Nash

Institute for Marine and Antarctic Studies, University of Tasmania, Private Bag 129, Hobart, TAS 7001, Australia

K. A. Alexander

International Centre for Island Technology, Heriot Watt University, Robert Rendall Building, Franklin Road,

Stromness, Orkney KW16 3AW, UK

J. Melbourne-Thomas

CSIRO Oceans and Atmosphere, Castray Esplanade,

Battery Point, TAS 7004, Australia on more than 'just' additional data and knowledge. Moreover, public support for science appears at an all-time low (Kreps and Kriner 2020) and the sciencepolicy gap is growing (Cvitanovic and Hobday 2018). "The ocean we need for the future we want" requires scientists and decision-makers to identify how to facilitate the use of available science and encourage the uptake of behaviours and the implementation of policies-at individual, local and global scales-that will leverage greater environmental benefit.

This Future Seas 2030 Special Issue is the product of a large-scale inter and transdisciplinary collaboration that includes ecologists, psychologists, public health and education experts, philosophers, oceanographers, climate modelers, economists, social scientists, engineers, mathematicians, natural resource managers and information and communications technology researchers, as well as governance, ethics, finance and insurance, and law and policy experts from 12 countries and 25 nationalities. A unique and fundamentally important aspect was the involvement and collaboration with Traditional knowledge holders and Indigenous scholars and Elders from 13 First Nations around the world through a Traditional and Indigenous Peoples' Working Group.

Collectively, this Special Issue explores possible futures for our oceans by 2030 for a series of 'key' societal challenges, from climate change, food security and biodiversity, through to issues of ocean governance, ocean literacy and the blue economy. Most papers explore a 'business-as-usual' future-what 
the future might look like if we continued to follow our current trajectory, and then a 'More Sustainable Future' - what our future could entail if we used available knowledge and technology to achieve a future more aligned with the United Nations Sustainable Development Goals (SDGs). Each paper then explores pathways to achieve that more sustainable future, considering and describing what actions we need to take to achieve the future we want. These action pathways provide a roadmap to a future where society can thrive whilst respecting the ocean's intrinsic limits. Our world is currently changing very rapidly and the future we create is a choice-but it is not a choice between transformation or not-transformations are already underway. Instead, it is a choice as to whether we can direct those changes toward a more positive outcome for the 8.5 billion people the planet will need to support by 2030 (UN 2019), and the coastal and ocean ecosystems they depend on (Blythe et al. 2018).

A Preface (Mustonen et al. 2021), this Editorial, and a detailed methods article (Nash et al. 2021a), provide information on our approach, and frame the Special Issue. The Traditional and Indigenous Peoples' Working Group was motivated to draft the Preface as 'before we begin, we should have a beginning - a place where the dialogue is equal'. The Preface articulates how their group knows the ocean and the non-human beings within it, highlighting that how we know the ocean leads us to the actions we take, how to 'be' with the ocean, and what is considered ethical or not in terms of our interactions with the ocean. Nash et al. (2021a) describe the strategic 'foresighting' technique adapted to develop interdisciplinary, evidence-informed plausible scenarios of the future by 2030 . This technique was used by most of the key challenge papers to articulate: (1) what the future could look like if current trends continue; and (2) what our future could look like if we more effectively used the data and knowledge currently available to us to push as far as possible towards achieving the SDGs. Nash et al. (2021a) also describe the 'backcasting' approach then used by each paper to generate a tangible plan for possible actions to undertake at local, regional, and global scales, if society chose to work towards a future more in line with the SDGs.

The papers in this 'Future Seas 2030' special issue have each explored potential scenarios of sustainable futures that are theoretically achievable for a range of key challenges for achieving and maintaining a healthy future global ocean, including issues relating to Indigenous rights and access (Fischer et al. 2021), climate change (Trebilco et al. 2021), biodiversity conservation (Ward et al. 2022) and species redistribution (Melbourne-Thomas et al. 2021), food security (Farmery et al. 2021), ocean literacy (Kelly et al. 2021), pollution (Willis et al. 2021), feedbacks between human and ocean health (Nash et al. 2021b), resource use (Bax et al. 2021 and Novaglio et al. 2021), and ocean governance (Haas et al. 2021). Each of these key challenges either explicitly or implicitly relates to the UN Decade of Ocean Science for Sustainable Development goals as well. Each challenge paper identifies 'drivers' relevant to that particular challenge, factors that will have a significant impact on the challenge, and that society has a high capacity to influence (see Nash et al. 2021a this issue). Paper teams were encouraged to use the PESTLE framework, to explore drivers in Political, Economic, Social, Technological, Legal, and Environmental spheres. The PESTLE framework was also used in the back-casting process to then derive potential actions to help navigate society towards the more sustainable futures (for full details see Nash et al. 2021a). The large interdisciplinary teams for each paper considered actions (and the actors) needed to achieve sustainable futures at local, regional, and global scales, and the broader Future Seas project was designed with the recognition that future ocean sustainability is a collective action problem requiring leveraging of behavioural insights (Cinner 2018).

Emergent themes across the special issue include the need for: (1) enhanced connection between people and the ocean to help engage and mobilise the public on action for ocean sustainability; (2) flexible, inclusive and coordinated ocean management and governance; (3) incentives (particularly financial) to help enhance and speed up sustainability transitions in a transparent, trustworthy and equitable manner; (4) improved marine environmental accounting; (5) strengthened Indigenous rights and access, and increased recognition of Indigenous knowledge and (6) accelerated and equitable deployment of technological solutions together with improved access to existing information about the oceans, and the communities and industries that depend on them. The papers in this issue also highlight the critical contribution of the social and behavioural sciences, the 
importance of boundary-spanning between science and policy, and the need to monitor progress in the implementation of actions in adaptation pathways. Importantly, issues of equity and justice, concepts that are understood differently between Western cultures and Traditional and Indigenous peoples, are also critical to consider when attempting to address changing ocean conditions and expanding human enterprise (key challenges). Alexander et al. (2021) provide an added dimension to this special issue by undertaking a deep dive into how the ocean futures identified in the challenge papers, and the proposed pathways to achieving these futures, help the SDGs to achieve higher or lower levels of equity.

As researchers and users of the oceans, many of us are predominantly preoccupied with immediate pressures. We don't often get the opportunity, or actively create the space, to think in a systematic, big picture way about (1) what the future that we are heading towards could look like, and (2) about different possible futures that we, collectively as society, might want to work towards instead. Moreover, scientists are often criticised for being 'purveyors of doom', possibly leading the public to feel overwhelmed and demotivated to take action towards change. As a result, scientists are actively being encouraged to be optimistic and more engaging (Cvitanovic and Hobday 2018). However, although everyone loves a success story (McAfee et al. 2019), based on current trajectories for many ocean issues (Halpern et al. 2017), optimism can sometimes be difficult to muster and may even feel hypocritical. Future Seas attempts to circumvent that conundrum in three ways: First, by using the process of futures thinking and scenario development to allow participants to explore the complexities of these ocean challenges in a new, motivating light. Second, by presenting paired futuresBusiness-as-Usual and More Sustainable-the project highlights the power of the choices we make today to direct transformations to the future we want. Third we provide visual elements (Fig. 1) to help support the 'mobilising narratives' when disseminating this work with the public and other stakeholders. Creative communication about the Future Seas initiative with the public through the use of performance and art has also enhanced dissemination of outcomes and prompted discussion and thinking around alternative futures (Fig. 2). Improved public understanding of the ocean and the importance of sustainable ocean use, or ocean literacy, is essential for achieving global commitments to sustainable development by 2030 and beyond, and so we also developed an ocean literacy toolkit (Fig. 3) to help address the challenge of improving societal connections to the ocean.

Ultimately, navigating a pathway to sustainable global ocean use and conservation will require a diverse range of actors and stakeholders across a wide range of scales to work together towards a shared purpose. This process will need to be underpinned by mechanisms to support and strengthen society's stewardship of, and connection to the oceans, and the co-creation of collective visions for our future oceans. This special issue is intended as a contribution towards this process of creating both shared visions and pathways for action, as part of the UN Ocean Decade. Collectively the papers within this Special Issue provide an inter and transdisciplinary research agenda, focused on real-world challenges and providing a clear foundation for future research activities to facilitate desirable transformative change for many of the key challenges facing our oceans. Human society is, and always has been, dependent on the oceans for our culture and livelihoods. Oceans provide a wide range of ecosystem services including production of oxygen, climate regulation, and resources to underpin millions of jobs in important industries such as fishing, mining, tourism, and shipping. Moreover, the ocean is a scientific, technological, economic and geopolitical frontier with substantial projected 'blue economy' growth, along with escalating demands and expectations (e.g. to provide nature-based solutions to climate change) over the coming decades. We are at a critical juncture for the oceans where there are major social, cultural, and political barriers to be overcome for the transformations needed. Creating and sharing inter and transdisciplinary visions of possible sustainable futures and providing pathways for attaining those (Hinkel et al. 2020) is hopefully a useful step towards enabling future generations to enjoy connection to, and benefits from, healthy productive ocean environments. 
Fig. 1 For each paper in this Special Issue, professional science communicators or artists were engaged to develop either graphical abstracts, or visual depictions of the two possible futures explored and described

\begin{tabular}{|c|c|c|}
\hline & $\begin{array}{l}\text { Business-as-usual } \\
\qquad 2030\end{array}$ & $\begin{array}{l}\text { More sustainable } \\
\qquad 2030\end{array}$ \\
\hline $\begin{array}{l}\text { Indigenous \& } \\
\text { Traditional } \\
\text { Peoples' } \\
\text { perspectives }\end{array}$ & 3 & Artcr \\
\hline Food for all & 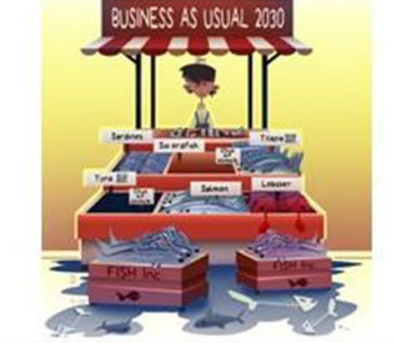 & MORE SUSTANALE WOSO \\
\hline $\begin{array}{l}\text { Offshore Blue } \\
\text { Economy }\end{array}$ & 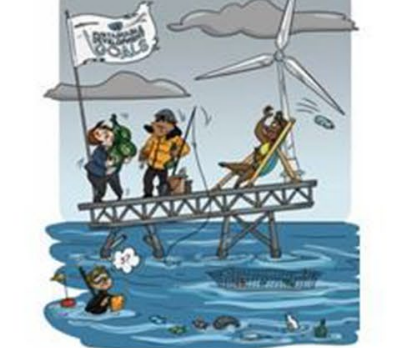 & 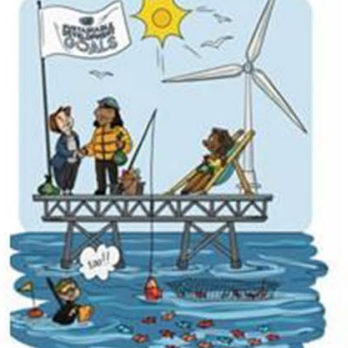 \\
\hline $\begin{array}{l}\text { Climate-driven } \\
\text { species } \\
\text { redistribution } \\
\text { Melbourne-Thomas } \\
\text { et al } 2021\end{array}$ & 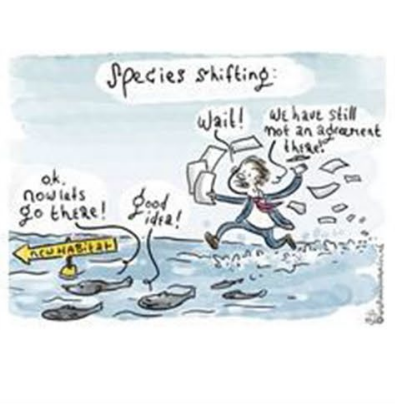 & 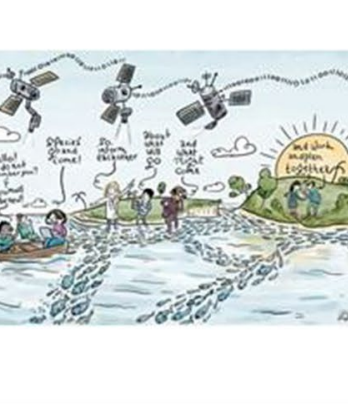 \\
\hline
\end{tabular}


Fig. 2 To help non-scientific audiences in a creative exploration of what our marine futures could look like by 2030, aspects of the Future Seas collaboration were integrated within, and told through, the lens of a high-stakes fiction thriller 'Full Metal Aquatic', made available online (www. FutureSeas2030.org). The fictional story is narrated in two different versions of the future, with the same scenes shown in business-as-usual vs more sustainable futures alternately throughout the story and each incorporating elements of the Future Seas Special Issue papers. This was designed to help the public visualise and more strongly connect to what our future could potentially look like, based on the choices we are actually making right now

\begin{tabular}{|c|c|c|}
\hline Characters & Business-as-usual & More sustainable \\
\hline Multi-use deep- \\
water ocean \\
facility
\end{tabular}




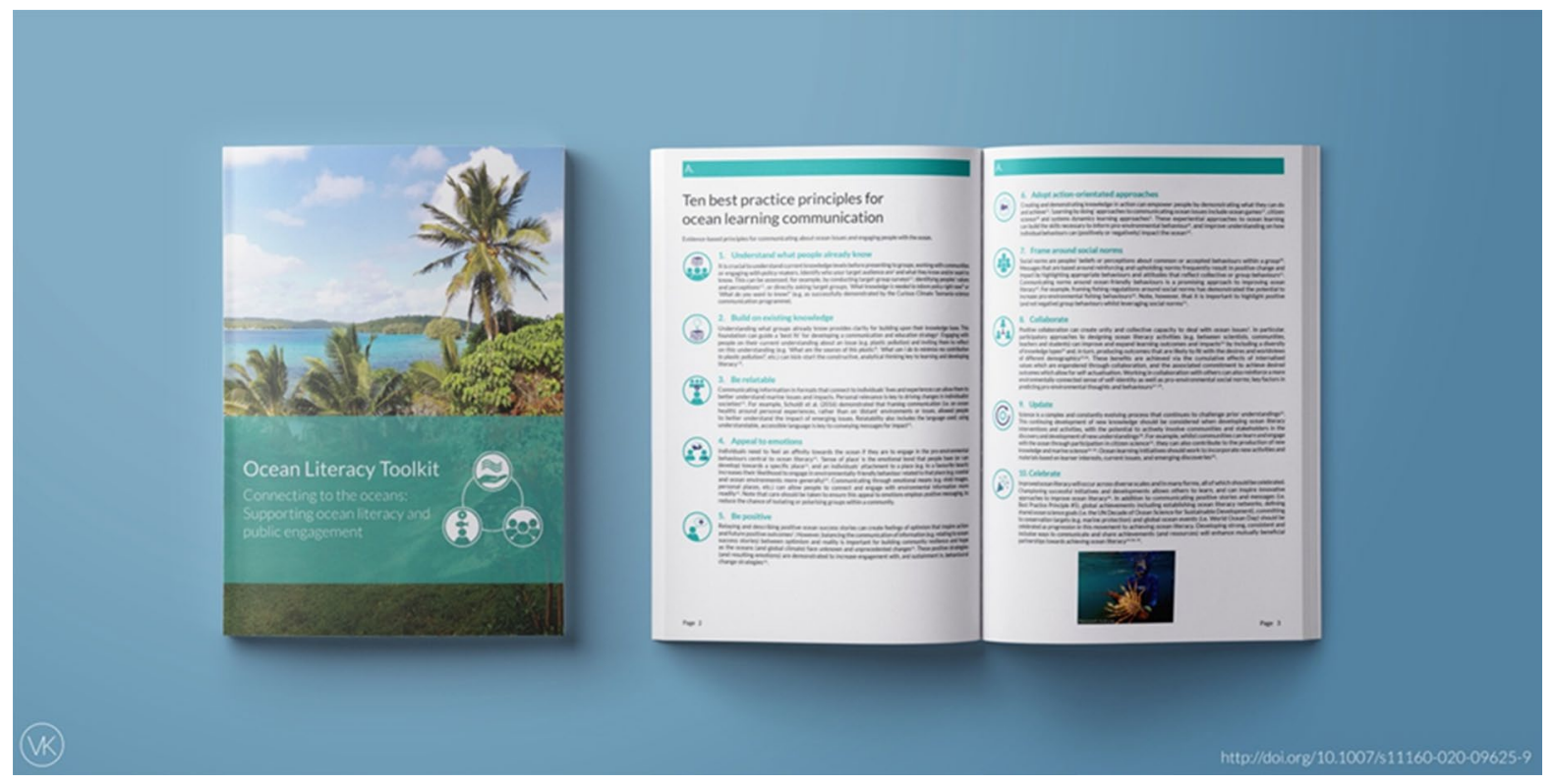

Fig. 3 Building upon 1/evidence-informed approaches to learning, 2/ frameworks for understanding communities and assessing ocean literacy activities, as well as 3/ practical examples of existing ocean literacy activities, Kelly et al. 2021 developed an Ocean Literacy Toolkit available in Appendix B as part of their synthesis of existing knowledge and perspec- tives on ocean literacy from a range of disciplines and sectors. When ocean literacy activities are tailored to relevant issues and communities, they increase community learning and engender attitudes of concern that can promote personal action (Gelcich et al. 2014)

\begin{abstract}
Acknowledgements Riawunna Centre at UTAS provided advice and support for the Indigenous and Traditional working group, and the Future Seas project as a whole. Funding for Future Seas was provided by the Centre for Marine Socioecology, IMAS, MENZIES and the College of Arts, Law and Education, and the College of Science and Engineering at UTAS. We acknowledge support from a Research Enhancement Program grant from the DVCR Office at UTAS. GP was supported by an ARC Future Fellowship. We are grateful to the 130 participants within the broader Future Seas project who participated in the workshops described in this special issue and contributed to the development of the methods, and to the Managing Editors Robert Stephenson and Jessica Blythe for their valuable guidance. We acknowledge and pay respect to the traditional owners and custodians of sea country all around the world and recognise their collective wisdom and knowledge of our oceans and coasts. We are in particular deeply grateful to the Indigenous and Traditional working group for their time, knowledge, trust and collaboration. Thank you to David Finnigan and Jordan Prosser for their 'Full Metal Aquatic' art-science interpretation of the Future Seas special issue, and Dean Greeno, Bas Köhler, Stacey McCormack from Visual Knowledge, and Animate Your Science for artwork, images and graphical abstracts.
\end{abstract}

\section{References}

Alexander KA, Fleming A, Bax N et al (2021) Equity of our future oceans: practices and outcomes in marine science research. Rev Fish Biol Fish. https://doi.org/10.1007/ s11160-021-09661-z

Blythe J, Silver J, Evans L et al (2018) The dark side of transformation: latent risks in contemporary sustainability discourse. Antipode 50:1206-1223. https://doi.org/ 10.1111/anti.12405

Bax N, Novaglio C, Maxwell KH et al (2021) Ocean resource use: building the coastal blue economy. Rev Fish Biol Fish. https://doi.org/10.1007/s11160-021-09636-0

Cinner J (2018) How behavioural science can help conservation. Science 362:889-890. https://doi.org/10.1126/ science.aau6028

Cvitanovic C, Hobday AJ (2018) Building optimism at the environmental science-policy-practice interface through the study of bright spots. Nat Commun 9:3466. https://doi. org/10.1038/s41467-018-05977-w

Farmery AK, Alexander K, Anderson K et al (2021) Food for all: designing sustainable and secure future seafood systems. Rev Fish Biol Fish. https://doi.org/10.1007/ s11160-021-09663-x 
Fischer M, Maxwell K et al (2021) Empowering her guardians to nurture our Ocean's future. Rev Fish Biol Fish. https:// doi.org/10.1007/s11160-021-09679-3

Gelcich S, Buckley P, Pinnegar JK et al (2014) Public awareness, concerns, and priorities about anthropogenic impacts on marine environments. Proc Natl Acad Sci USA 111:15042-15047. https://doi.org/10.1073/pnas.14173 44111

Haas B, Mackay M, Novaglio C et al (2021) The future of ocean governance. Rev Fish Biol Fisheries 0123456789:1-18. https://doi.org/10.1007/s11160-020-09631-x

Halpern BS, Frazier M, Afflerbach J et al (2017) Drivers and implications of change in global ocean health over the past five years. PLOS ONE 12:e178267

Hinkel J, Mangalagiu D, Bisaro A et al (2020) Transformative narratives for climate action. Clim Change 160:495-506. https://doi.org/10.1007/s10584-020-02761-y

IPCC (2019) IPCC Special Report on the Ocean and Cryosphere in a Changing Climate. In: Pörtner H-O, Roberts DC, Masson-Delmotte V, Zhai P, Tignor M, Poloczanska E, Mintenbeck K, Alegría A, Nicolai M, Okem A, Petzold J, Rama B, Weyer NM (eds), In press

Jouffray JB, Blasiak R, Norström AV et al (2020) The blue acceleration: the trajectory of human expansion into the ocean. One Earth 2:43-54

Kelly R, Evans K, Alexander K et al (2021) Connecting to the oceans: supporting ocean literacy and public engagement. Rev Fish Biol Fish Online. https://doi.org/ 10.1007/s11160-020-09625-9

Kreps SE, Kriner DL (2020) Model uncertainty, political contestation, and public trust in science: evidence from the COVID-19 pandemic. Sci Adv. https://doi.org/10. 1126/sciadv.abd4563

McAfee D, Doubleday ZA, Geiger N, Connell SD (2019) Everyone loves a success story: optimism inspires conservation engagement. Bioscience 69:274-281

Melbourne-Thomas J, Audzijonyte A, Brasier MJ et al (2021) Poleward bound: adapting to climate-driven species redistribution. Rev Fish Biol Fish. https://doi.org/10. 1007/s11160-021-09641-3

Mustonen T, Maxwell KH, Mustonen K et al (2021) Who is the ocean? Preface to the future seas 2030 special issue. Rev Fish Biol Fish. https://doi.org/10.1007/ s11160-021-09655-x

Nash KL, Alexander K, Melbourne-Thomas J et al (2021a) Developing achievable alternate futures for key challenges during the UN Decade of Ocean science for sustainable development. Rev Fish Biol Fish Online. https://doi.org/10.1007/s11160-020-09629-5

Nash KL, van Putten I, Alexander K et al (2021b) Oceans and society: feedbacks between ocean and human health. Rev Fish Biol Fish. https://doi.org/10.1007/ s11160-021-09669-5

Novaglio C, Bax N, Boschetti F et al (2021) Deep aspirations: towards a sustainable offshore Blue Economy. Rev Fish Biol Fish 6:1-22. https://doi.org/10.1007/ s11160-020-09628-6

Trebilco R, Fleming A, Hobday AJ et al (2021) Warming world, changing ocean: mitigation and adaptation to support resilient marine systems. Rev Fish Biol Fish. https:// doi.org/10.1007/s11160-021-09678-4

UN (2019) Special edition: progress towards the Sustainable Development Goals, Report of the Secretary-General. UN Economic and Social Council, United Nations

Ward D, Melbourne-Thomas J, Pecl GT, et al (2022) Safeguarding marine life: conservation of biodiversity and ecosystems. Reviews in Fish Biology and Fisheries

Willis KA, Serra-Goncalves C, Richardson K et al (2021) Cleaner Seas: reducing marine pollution. Rev Fish Biol Fish 8:1-22. https://doi.org/10.1007/s11160-021-09674-8

Publisher's Note Springer Nature remains neutral with regard to jurisdictional claims in published maps and institutional affiliations. 